This item was submitted to Loughborough's Research Repository by the author.

Items in Figshare are protected by copyright, with all rights reserved, unless otherwise indicated.

\title{
Developing safety signs for children on board trains
}

PLEASE CITE THE PUBLISHED VERSION

http://dx.doi.org/10.1016/j.apergo.2011.05.012

\section{PUBLISHER}

(c) Elsevier

\section{VERSION}

AM (Accepted Manuscript)

\section{PUBLISHER STATEMENT}

This work is made available according to the conditions of the Creative Commons Attribution-NonCommercialNoDerivatives 4.0 International (CC BY-NC-ND 4.0) licence. Full details of this licence are available at: https://creativecommons.org/licenses/by-nc-nd/4.0/

\section{LICENCE}

CC BY-NC-ND 4.0

\section{REPOSITORY RECORD}

Waterson, Patrick, Cara Pilcher, Sian Evans, and Jill Moore. 2019. "Developing Safety Signs for Children on Board Trains". figshare. https://hdl.handle.net/2134/16041. 


\title{
DEVELOPING SAFETY SIGNS FOR CHILDREN ON BOARD TRAINS: FINDINGS FROM GREAT BRITAIN
}

\author{
Patrick Waterson, Cara Pilcher \\ Department of Ergonomics (Human Sciences) \\ Loughborough University, UK \\ Siân Evans and Jill Moore \\ Rail Safety and Standards Board (RSSB), \\ London, UK
}

\begin{abstract}
Every year a significant number of young children are injured as a result of accidents that occur on board trains in Great Britain. These accidents range from being caught in internal doors, slips, trips and falls and injuries caused by seats. We describe our efforts working with RSSB to design a new set of safety signs in order to help prevent such accidents occurring. The research involved running a set of workshops with young school children (aged 4-10, $\mathrm{n}=210$ ) and showing them examples of existing train signs and gathering the requirements for new designs. A second set of workshops with these children was used to evaluate the new signs based on the outcomes from the earlier workshop. We describe our findings alongside a set of outline guidelines for the design of safety signs for young children, A final section outlines possibilities for future research.
\end{abstract}

\section{INTRODUCTION}

The study of warning signs has a well established history within human factors and ergonomics. A range of factors have been shown to determine the effectiveness of designs for warning signs (Laughery, 2006). Barlow and Wogalter (1993) for example, found that warnings printed in bigger print enhanced later recall (i.e., encoding). The use of pictorials and written signal words (e.g., DANGER) in warnings has also been investigated in detail. Many of these types of findings have been used to form design standards and guidelines. The ANSI (1998) Z535 document for example, states that the following four points should be taken into consideration when designing warnings:

- A signal word such as DANGER, WARNING or CAUTION to attract attention to the warning and give an idea of the potential level of hazard;

- A hazard statement which briefly describes the nature of the hazard;

- A description of the possible consequences associated with noncompliance;

- Instructions for how to avoid the hazard.

Research centered around the C-HIP (Communication-Human Information processing) framework also indicates that aside from factors relating to the design and location of warnings, there are a number of behavioral and personal factors that influence the effectiveness of warnings (Wogalter et al., 1999). For example, warnings are more likely to be noticed and read if they are especially relevant to the specific group or individual. In other cases the extent to which a product is perceived as a hazard, irrespective of the design of the accompanying warning has been shown to particularly important in certain contexts (e.g., perceptions by parents of the dangers of children's toys - Davies et al., 1998).

\section{Children and warnings}

Few explicit guidelines exist for the design of warnings for younger children. One of the key lessons from the available research is that because of the limited cognitive abilities of children, particularly the very young, warnings need to be designed very differently as compared to those targeted at adults. Kalsher and Wogalter (2008) suggest that some aspects of guidelines aimed at adult populations can be adopted for use with younger children, these include:

- Making warnings "stand out" - warnings should generally incorporate characteristics such as the use of bright colors and the use of contrast in order to capture the child's attention. It is also important that the characteristics of the labeling do not draw children into a false sense of security (i.e., leading them to believe the product is safer than it really is);

- Using pictorial symbols (pictograms) - children who are familiar with a pictorial are more likely to understand and comply than children who are not.

- The importance of evaluation and testing of warning designs - designers and manufacturers of warnings should aim as much as possible to systematically evaluate product warning in order to ensure they are achieving the intended goal of hazard control and not producing any harmful side effects (e.g., attracting children to potential hazards as opposed to deterring them from the hazards).

\section{Study background and aims}

In the last few years within GB there has been a number of new recommendations made regarding the design of trains and 
equipment used by passengers. Many of these recommendations have come about as a result of incidents and accidents involving trains (e.g., Cullen, 2001). In 2008 two GB-based train operators approached RSSB in order to ask them to investigate and identify how best to communicate non-emergency safety message to children (RSSB, 2009). The train operators had become aware of a number of incidents involving children when using vestibule doors, flip-up seats and hand rails on board trains. RSSB, in collaboration with Loughborough University, was asked to develop safety signs that could be displayed on rolling stock that might more adequately communicate safety messages to young children between 5-10 years of age. The current study aimed to meet this objective and has three aims:

(1) To identify the prevalence and main incident types involving children between 4-10 years of age on board trains in GB;

(2) To assess the comprehension levels of children between 5-10 years of age with regard to current non-emergency signs on board trains; and,

(3) To design and evaluate a set of new signs that are effective in communicating safety messages to children of this age group.

\section{METHODS}

\section{Accident and incidence data analysis}

In order to identify the main incident types involving young children an analysis of national safety risk data using the RSSB Safety Management Information System (SMIS) for the period January, 2003 - March, 2008 was carried out. The database contains accident reports relating to all of the train operating companies in GB.

\section{Workshops with children}

The workshops were run at a primary school and took place between February and April 2009. In total 210 children across 7 different classes and aged between 4-10 took part. The two workshops took the form of a set of 7 classroom discussions over two separate time periods. Workshop 1 focused on the evaluation of existing safety signs and took place at the beginning of February, 2009. Workshop 2 focused on the evaluation of a new set of safety signs which had been designed on the basis of the outcomes from the earlier workshop and took place at the end of April, 2009.

Both workshops involved the same children and their teachers. Workshops with the youngest children (4-6 year olds) lasted on average between 20-30 minutes. With older children (7-10 year olds) the workshops lasted longer (45-60 minutes). This was due to difficulties in capturing the attention of younger children over longer time periods and the fact that they are easily exhausted by too much interaction and questioning.
During Workshop 1 the classroom discussions took a different format depending on the age range of the children in a particular class. For example, the younger children (4-6 year olds) were introduced to the classroom discussion by being presented with a toy train inside a soft bag. This interactive approach followed the procedure of other research which has shown that these types of procedure can be used to engage the children and to stimulate conversation amongst them (Mauthner, 1997). The children were asked to pass the bag to each other and to feel the bag to guess what was inside.

A similar activity was used with the older children (7-10 year olds), they were asked to imagine that Hannah Montana, a fictional pop star, had never travelled on a train before but was visiting her aunt. The children were asked to suggest precautions Hannah could take to stay safe while travelling on trains. Once the introductions had been covered and the children were engaged, the discussion moved onto eliciting children's comprehension of signs. The activity then moved onto evaluating existing safety signs on rolling stock (an example is shown in figure 1).

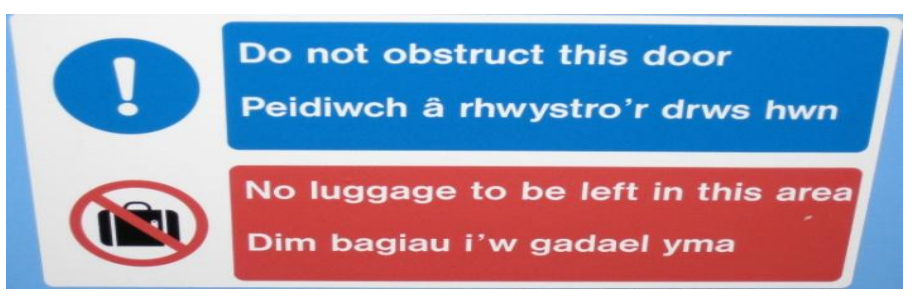

Figure 1: Example of existing train signs used in workshop 1

The children were asked if they understood the safety message and also to discuss whether they found the signs easy or difficult to understand. Specific questions about the meaning of the pictograms, text, characters, use of color and layout were also used at the end of the workshop

In Workshop 2 the children were asked to evaluate a set of the new safety signs that had been developed subsequent to Workshop 1. In order to determine the success or failure of a particular design, a number of key criteria were considered and included:

- To what extent do the children understand the intended safety message?

- To what extent do the children understand the pictogram/text?

- What is the effect of using a safety character to reinforce positive Behaviour?

- What is the effect of using different colors within the signs and is the sign likely to influence children's behavior? 


\section{FINDINGS}

\section{Accident and incidence data}

Analysis of the dataset indicated that the use of vestibule doors contributed most to the total number of accidents (37\%), followed by 'strike against object' (19\%) and accidents involving the use of seats $(16 \%)$. Most accidents occur to children at the weekend with reported incidents increasing from Fridays to reach a peak on Saturdays and Sundays. A higher proportion of incidents are reported during the school summer holidays. These incidents occur to children across all geographic locations of the GB rail network and most train operating companies have reported at least one incident occurring to children on board their rolling stock.

The analysis of the accident and incident data was used to provide a basis for deciding to target safety signs at the reduction of accidents in specific parts on board the train (e.g., doors and seats). As a result different formats for existing and new types of safety signs which related to these specific parts of the train were used in Workshops 1 and 2. These formats include posters, small signs and labels.

\section{Outcomes from the workshops}

A clear outcome from the Workshop 1 was that across all age groups the children found existing safety signs very difficult to comprehend. The use of words such as 'CAUTION' and 'ATTENTION' in some signs for example, was too complex for many of the older children to read. Most of the older children who could read could not give an accurate description of what the words meant. In general, signs which were made up only of words were not well understood. By contrast, signs which contained pictograms or illustrations were much easier to comprehend, particularly where the text was reinforced by punctuation marks or contained other symbols (e.g., a medical cross). In addition, children of all age groups could explain the meaning of signs where a person of figure had been drawn. Comprehension was further improved when the facial expression of the person could easily recognized (e.g., a smiling or crying expression).

The use of color as part of the safety sign proved to be an important way of conveying safety messages. For example, all age groups recognized that 'red' meant 'danger' and 'green' signaled something that was 'safe'. Some of these associations were related to safety campaigns for children (e.g., the UK road crossing campaign 'the Green Cross Code'), or other schoolrelated associations (e.g., 'red' and the symbol ' $\mathrm{X}$ ' are associated with poor marks on homework). These findings were then used to form an outline set of design requirements for a set of new safety posters which was later evaluated in Workshop 2 (an example is shown in figure 2).

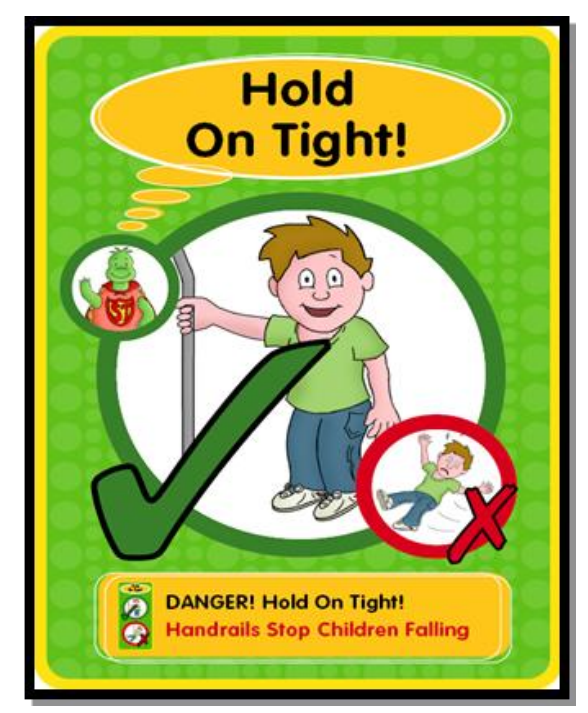

Figure 2: Example of poster designed using requirements gathered in Workshop 1

The design prototypes were generally well received by all of the children in Workshop 2. The use of pictograms to represent children and 'superheroes' shown in figure 2 proved to be popular and successful in conveying safety messages. In other cases, the designs proved less successful. For example, one of the posters showed a train guard pointing a finger and this was interpreted as 'telling them off' as compared to the original intention of signaling good behavior. Similar misunderstandings were present in other aspects of the prototypes. For example, a child in the poster was interpreted as being upset because he couldn't balance himself on the seat instead of the original intention of conveying the message 'do not stand on the seats'.

A number of specific design suggestions were made by the children as a result of evaluating the prototype designs:

- Some examples of the posters presented an image solely of 'what not to do'. The children suggested that signs should include both 'right' and 'wrong' pictograms, or at least 'good behavior' and never 'bad behavior' alone;

- The 'superhero' should be positioned closer to the 'tick' symbol as this would reinforce safe behavior;

- Older children suggested that the 'superhero' should be incorporated into the main picture as this would help to establish its status as a role model;

- Simple phrases such as 'Be Safe', 'Stop' and 'Look' were preferred by the older children as these were simple to read and understand;

- Including in the sign both the result of unsafe behavior (e.g., a picture of a child falling over) and the cause of the behavior (i.e., not holding onto the train bar), instead of not including these elements in both pictures.

The main outcome from Workshop 2 was a revised set of designs for safety posters and signs (an example is shown in figure 3 ). 


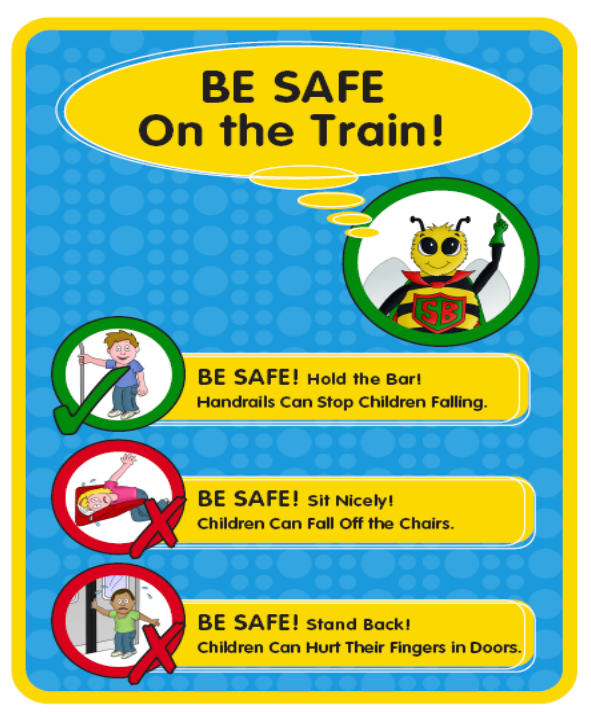

Figure 3: Example poster designed based on the outcomes from Workshop 2

\section{DISCUSSION}

One key lesson from the project is that there is often a big gap between the intentions of the designer and the way in which a feature of the design is interpreted by a child. We came across a number of examples where an aspect of the design that seemed relatively straightforward from an adult's point of view, was seen very differently (and sometimes very creatively) by the children in the workshops. These, alongside other observations made during the study reinforce the need for careful and sensitive evaluation and testing of signs, particularly as it applies to very young children (Kalsher and Wogalter, 2008).

\section{Outline guidelines for the design of signs for children}

The other key lessons that we have gathered from the study can be viewed as a set of outline guidelines which require further evaluation and testing in different settings and with different goals to those described in the study. These guidelines include:

- $\quad$ Keep the language used in signs as simple as possible. We found that 8-9 year old children were unable to understand the meanings of words such as 'caution'. Similarly, children aged 9-10 were unable to accurately explain the words such as 'obstruct';

- Use a minimum of words: the children said that they often ignored signs that had a lot of written text, particularly when the text size was small;

- $\quad$ Avoid 'abstract' concepts or terminology: Some children struggled with the term 'flip-up seat' as they could not relate this to their everyday surroundings, as a result they preferred the term 'chair';

- Use pictograms where possible to reinforce the safety message: The use of pictograms proved to be a highly effective method for communicating safety information to the children in the study. Children were better able to explain the safety message in the signs where an illustration of a person was used, especially where the facial expression conveyed a particular emotion associated with good or bad behavior.

- Use examples of pictograms that effectively illustrate 'good' and 'bad' behavior: In the case of our study this translated into depictions of children smiling, sitting in their seats and holding onto the hand rail. The children were more responsive to the images where children were depicted as having round faces, with big eyes and smiles, as they appeared more child-like. Examples of pictograms that effectively illustrate 'bad' behavior included children falling off their seats, getting their fingers trapped in the doors, and wearing bandages. A cartoon image of a child crying reinforced the message that the child was hurt. Using facial expressions was effective in communicating safe and unsafe behavior. The youngest children (4-5 year olds) especially relied on the emotion shown to help them accurately interpret the meaning of the sign.

- Use symbology that appeals to children: We found that the use of symbols such as ticks and crosses was an effective means of conveying safe and unsafe behavior. Ticks and crosses must be large enough in relation to the picture to aid understanding of the safety message.

- Use colors to reinforce the safety message: We found that young children tend to have very strong associations with colors. For example, children found a blue background more effective than any other color in highlighting safety, as it contrasted with the green tick and red cross to make them look more prominent.

- Use safety characters to help convey the safety message: The children were more responsive to safety signs that included a 'safety character' to reinforce the safety message by pointing to the section of the sign which refers to the correct behavior eg holding onto the handrail. The signs that included 'safety characters' such as a superhero were more eye-catching, and attracted the children's attention. The children also felt that they could relate to a 'safety character' or super hero as they are generally understood to be moral individuals who help keep children safe.

\section{Study limitations and future work}

The study needs to be seen in the light of a number of limitations. A key limitation is that in an ideal world we would have not involved the same groups of children in workshops 1 and 2 . We acknowledge that separating out the groups involved in design and evaluation would have improved the generalizability of our results. Given the difficulties and practicalities in organizing and running workshops with school children this was not possible within the present study. Nevertheless, we believe our findings demonstrate a number of valuable insights into the design of safety signs for children. Likewise, there is a need for further evaluation of the outline guidelines put forward in the paper. For example, as pointed out by Kalsher and Wogalter (2008) it may be that in some cases that the use of cartoon characters (or 
'superheroes' as in this study) serves to promote unsafe behavior (e.g. in the case of chemical or drug labels), as compared to preventing it. In other words, the outline guidelines should be treated with a degree of caution. They may not be appropriate for all contexts and in this case the issue of evaluation of testing is of paramount importance.

A third limitation is that our study only describes the design and evaluation of signs for children. There is a need to carry out behavioral testing in some form or another in order to demonstrate the likelihood that the new safety signs actually influence children's behavior when they are traveling on trains, as compared to sitting in a classroom. This type of testing is difficult to do, but might be achieved through an observational study over time, alongside the analysis of more specific patterns of safety violations by children and their incidence.

Future work should also be conducted not only on the influence of signs on children's behavior on trains, but also how well designed signs influence the patterns of behavior of caregivers and their interaction with children (Wogalter, email communication). At the moment there are plans to implement the signs by a number of train operating companies in GB and we hope to report at some later stage on a follow up study of the efficacy of the designs described in this paper.

\section{ACKNOWLEDGEMENTS}

The work described in the paper was undertaken as part of the rail industry's research and development programme, managed by RSSB, and funded by UK Department for Transport. A separate report published by RSSB in 2009 ("Research Report T826 Developing safety signs for children on board trains") is available at the following web address:

http://www.rssb.co.uk/Proj_popup.asp?TNumber=826\&Parent=8 $1 \&$ Ord

\section{REFERENCES}

ANSI (1998). Accredited Standards Committee on Safety Signs and Colors. Z535.1-5, Washington, DC: National Electrical Manufacturers Association.

Barlow, T. and Wogalter, M.S. (1993). Alcohol beverage warnings in magazine and television advertisements. Journal of Consumer Research, 20, 147-155

Cullen, Lord (2001) The Ladbroke Grove Rail Inquiry: Part 1 Report. London: HSE Books. Available at http://www.railreg.gov.uk/upload/pdf/incident-ladbrokegrove-lgri1-optim.pdf (last accessed 21st January 2010).

Davies, S., Haines, H., Norris, B. and Wilson, J.R. (1998). Safety pictograms: are they getting the message across? Applied Ergonomics, 29, 15-23.
Kalsher, M.J. and Wogalter, M.S. (2008). Warnings: hazard control methods for caregivers and children. In R. Lueder and V.J. Berg Rice (Eds.), Ergonomics for Children: Designing Products and Places for Toddlers to Teens. London: Taylor and Francis.

Laughery, K.R. (2006). Safety communications: Warnings. Applied Ergonomics, 37, 467-478

Mauthner, M. (1997), Methodological aspects of collecting data from children: lessons from three research projects. Children and Society, 11, 16-28.

Wogalter, M.S., DeJoy, D.M. and Laughery, K.R. (1999). Warnings and Risk Communication. London: Taylor and Francis. 